\title{
PERSFEKTIF SOSIAL EKONOMI PETANI PADI DI DESA KANJILO KECAMATAN BAROMBONG KABUPATEN GOWA
}

\author{
Amruddin ${ }^{1)}$ dan Asriyanti Syarif ${ }^{2)}$ \\ Program Studi Agribisnis Universitas Muhammadiyah Makassar. \\ 1)amruddin@unismuh.ac.id \\ 2)asriyanti.syarif@unismuh.ac.id
}

\begin{abstract}
Ringkasan
Penelitian mengkaji pendapatan petani dan mengidentifikasi persfektif petani secara ekonomi dan sosial dalam usahatani padi di Desa Kanjilo Kecamatan Barombong Kabupaten Gowa.Penelitian dilakukan di Desa Kanjilo yang merupakan daerah perbatasan Kabupaten Gowa dan Kotamadya Makassar dengan pertimbangan bahwa daerah ini sebagian penduduknya masih mempertahankan lahan mereka untuk membudidayakan tanaman padi ditengah arus pembangunan daerah perbatasan dan adanya alih fungsi lahan dari pertanian ke perumahan atau industri. Populasi dalam penelitian ini adalah petani padi dan sampel yang diambil dilakukan secara sengaja (Purposive) dengan jumlah sampel 30 orang petani yang dijadikan responden dengan pertimbangan telah melakukan usahatani padi selama kurun waktu 10 tahun.Hasil penelitian menunjukkan bahwa pendapatan petani dari usahtani padi Rp.19.201.386/Ha/Musim, petani melakukan usahatani padi 2-3 kali selama setahun.Usahatani cukup menguntungkan bagi petani namun hasil yang diperoleh belum dapat memenuhi kebutuhan hidup mereka disebabkan tingginya biaya hidup.Oleh karena itu dari 30 responden melakukan kegiatan off farm sebagai tenaga buruh bangunan, supir, berdagang. Alasan mereka mempertahankan tanah pertanian untuk memenuhi konsumsi pangan, mempertahankan budaya dan tradisi dalam bercocok tanam, serta masih dianggap sebagai alat dalam stratifikasi sosial.
\end{abstract}

Kata kunci : sosial ekonomi, persfektif petani, padi 


\title{
SOCIO-ECONOMIC PERSPECTIVE OF RICE FARMERS IN KANJILO VILLAGE BAROMBONG DISTRICT GOWA REGENCY
}

\begin{abstract}
Study examine the income of farmers and identify the perspective of farmers economically and socially in rice farming in Kanjilo Village, Barombong District, Gowa Regency. The study was conducted in Kanjilo Village, which is a border area of Gowa Regency and Makassar city, with the consideration that this area is part of the population still maintaining their land to cultivate rice in the midst of the development of the border area and the conversion of land from agriculture to housing or industry. The population in this study were rice farmers and the sample taken was done intentionally (Purposive) with a total sample of 30 farmers who were respondents as consideration having done rice farming for a period of 10 years.The results showed that farmers' income from rice farming was Rp.19,201,386/Ha/Season, farmers did rice farming 2-3 times during the year. Farming was quite beneficial for farmers but the results obtained were unable to meet their needs because of the high cost of living. Therefore, of the 30 respondents doing off farm activities as construction workers, drivers, and traders. The reason they maintain agricultural land to meet food consumption, maintain culture and tradition in farming, and is still considered a tool in socialstratification. Keywords: socio economic, farmers perspective, rice
\end{abstract}

Keywords: socioeconomic, farmers perspective, rice

\section{PENDAHULUAN}

Sektor pertanian merupakan sektor yang masih memberikan kontribusi dalam perekonomian Indonesia dalam hal penyediaan tenaga kerja, lahan pertanian yang masih ada dan dapat digarap oleh petani meskipun luasannya kecil, komoditas dapat dipasarkan untuk memenuhi kebutuhan konsumsi masyarakat serta konsumsi pangan dalam rangka upaya ketahanan pangan. Pelaksanaan pembangunan seiring dengan pertumbuhan jumlah penduduk dan peningkatan konsumsi per kapita yang dirangsang dengan produksi padi semakin sulit ditingkatkan akibat meningkatnya konversi lahan sawah ke penggunaan non pertanian akan memperbesar masalah pangan, kenaikan pendapatan rumah tangga, sementara kebutuhan beras terus mengalami peningkatan (Bambang, 2005).

Tanaman padi merupakan tanaman yang dibudidayakan oleh sebagian besar penduduk Indonesia baik yang bemukim di wilayah pedesaan dan wilayah perbatasan antara pedesaan dan perkotaan.Tanaman tanaman padi dibudidayakan untuk memenuhi kebutuhan pangan yang sebagian besar penduduk masih mengkonsumsi hasil dari tanaman padi berupa beras.Tanaman padi merupakan komoditas strategis yang menyangkut hajat hidup orang banyak. Usahatani padi di Kecamatan Bontonompo merupakan sawah beririgasi sebanyak 1.539 Ha dan sawah tadah hujan sebanyak 111 Ha. Jumlah Luas sawah sebesar $1.650 \mathrm{Ha}$ (BPS, 2017).

Usahatani padi yang dilakukan di Desa Kanjilo Kecamatan Barombong Kabupaten Gowa adalah wilayah perbatasan yang dekat dengan wilayah perkotaan terkendala dengan luasan yang terbatas, adanya konversi lahan yang tidak dapat dihindarkan dari adanya perkembangan pembangunan yang merubah lahan pertanian menjadi kawasan perumahan dan industri. Konversi lahan merupakan perubahan dari fungsi lahan yang semula digunakan untuk sektor 
pertanian beralih fungsi ke sektor non pertanian (industri dan perumahan) disebabkan dengan pesatnya pembangunan yang terjadi diwilayah perkotaan hingga wilayah pinggiran kota (daerah penyangga) dari kota.

Sedangkan lahan pertanian merupakan merupakan lahan yang digunakan untuk melakukan usahatani khususnya tanaman padi. Benturan kepentingan antara usahatani padi dan perkembangan pembangunan yang berkembang diwilayah perbatasan menghadirkan persfektif bagi petani. Persfektif merupakan konteks sistem dan persepsi visual adalah cara bagaimana obyek terlihat pada mata manusia berdasarkan atas spasial, atau dimensi dan posisi mata relatif terhadap obyek. Desa Kanjilo merupakan salah satu daerah perbatasan yang ada di Sulawesi Selatan yang dekat dengan Kotamadya Makassar, sebagian dari masyarakatnya berprofesi sebagai petani dan juga melakoni pekerjaan lain diluar dari kegiatan on farm, mempertahankan lahan pertanian mereka untuk melakukan usahatani padi menghadirkan persfektif mereka secara sosial Ekonomi.

\section{METODE PENELITIAN}

\section{Tempat dan Waktu Penelitian}

Penelitian dilakukan di Desa Kanjilo dengan pertimbangan karena desa ini merupakan daerah perbatasan Kabupaten Gowa dan Kotamadya Makassar yang sebagian masyarakat masih bekerja disektor pertanian sebagai petani dengan melakukan usahatani padi. Penelitian dilakukan pada bulan Maret Hingga Mei 2019.

\section{Teknik Pengambilan Sampel}

Dilakukan secara sengaja (Purposive sampling) dengan mengambil 30 orang petani dengan pertimbangan bahwa mereka telah melakukan usahatani selama 10 tahun selain itu memiliki pekerjaan lain diluar dari kegiatan onfarm.

\section{Sumber dan Jenis Data}

Sumberdata diperoleh dari wawancara petani dengan menggunakan quisioner (data primer) dan didukung dari BPS dan lain-lain (data sekunder). Jenis data secara kualitatif (persfektif petani secara sosial dan ekonomi) sedangkan secara kuantitatif (perhitungan pendapatan).

\section{Analisis Data}

Pendapatan petani dalam melakukan usahatani padi dilakukan dengan analisis pendapatan yaitu (Ken Suratiyah, 2011) :

$$
\begin{aligned}
& \mathrm{PD}=\mathrm{TR}-\mathrm{TC} \\
& \mathrm{TR}=\mathrm{P} \mathrm{X} \mathrm{Q} \\
& \mathrm{TC}=\mathrm{BT}+\mathrm{BV}
\end{aligned}
$$

Dimana :

$\mathrm{PD}=$ Pendapatan $(\mathrm{RP})$

$\mathrm{TR}=$ Penerimaan $(\mathrm{RP})$

$\mathrm{TC}=$ Total biaya $(\mathrm{Rp})$

$\mathrm{P}=\operatorname{Harga}(\mathrm{RP})$

$\mathrm{Q}=\operatorname{Jumlah}(\mathrm{kg})$

$\mathrm{BT}=$ Biaya tetap $(\mathrm{RP})$

$\mathrm{BV}=$ Biaya Variabel (RP)

Persfektif petani secara sosial dan ekonomi dilakukan secara deksriptif. Menurut Sugiyono (2010), metode dalam meneliti status sekelompok manusia, suatu obyek, kondisi, 
sistem pemikiran ataupun peristiwa pada masa sekarang. Tipe penelitian ini berusaha menerangkan fenomena sosial tertentu.

\section{HASIL DAN PEMBAHASAN}

\section{Karakteristik Responden}

\section{a. Berdasarkan Umur}

Responden dalam penelitian ini berada pada interval umur 25 tahun hingga 60 tahun. Kelompok umur 42 tahun hingga 48 tahun merupakan yang paling dominan di antara kelopok umur yang lain. Ini menunjukkan bahwa petani responden merupakan petani yang berada di usia produktif, dari segi fisik cukup kuat dan memiliki kematangan berfikir untuk melakukan kegiatan usahatani padi.

\section{b. Berdasarkan Pendidikan}

Responden dalam penelitian ini memiliki pendidikan mulai dari tidak tamat sekolah dasar, tamatan SD, SMP, dan SMA. Responden yang tidak tamat SD sebanyak 4 orang, yang tamat SD sebanyak 15 orang, SMP sebanyak 7 orang, SMA sebanyak 4 orang. Responden dominan tamatan SD, sehingga dari segi pendidikan tergolong rendah. Hal ini pula yang melatar belakangi mereka mengeluti pekerjaan sebagai petani. Tingkat pendidikan yang dominan rendah mendorong mereka bertahan disektor pertanian.

\section{c. Berdasarkan Pengalaman Usahatani}

Responden dalam penelitian ini memiliki pengalaman usahatani 10 tahun hingga 40 tahun. Pengalaman usahatani yang telah tergolong lama, menggambarkan mereka telah berpengalaman dalam melakukan usahatani padi serta pekerjaan sebagai petani merupakan pekerjaan yang memberikan penghidupan dan ketersediaan pangan. Mereka telah paham betul seluk beluk berusahatani padi serta kendala yang mereka hadapi.

\section{d. Berdasarkan Luas Lahan}

Responden dalam peneltian ini memiliki luas lahan $<1$ ha, Mereka rata-rata memiliki lahan berkisar 0,1 Ha hingga 0,8 ha. Berdasarkan luasan lahan yang di miliki tergolong kecil untuk ukuran dalam melakukan usahatani di sektor pertanian, namun hal ini tidak menyurutkan mereka untuk tetap bekerja pada usahatani padi dengan persfektif mereka dari segi ekonomi dan sosial.

\section{e. Berdasarkan jumlah tanggungan Keluarga}

Responden dalam penelitian ini memiliki jumlah tanggungan keluarga dimulai dari 2 orang tanggungan hingga 9 orang jumlah tanggungan. Adanya tanggungan keluarga yang sedikit dan ada yang banyak mendorong mereka melakukan usahatani padi (on farm) dan bekerja diluar sektor pertanian (off farm) guna memenuhi kebutuhan keluarga utamanya dalam pemenuhan kebutuhan akan pendidikan anak.

\section{Pendapatan Usahatani Padi}

Kegiatan usahatani menghasilkan produksi dalam bentuk gabah kering giling dengan harga jual berkisar Rp. 4.000/kg hingga Rp. 5.000/kg. Produksi yang dihasilkan petani berkisar $5.686 \mathrm{~kg} / \mathrm{ha}$ dalam satu musim. Penerimaan diperoleh dari penjualan hasil dari padi dikalikan dengan harga. Sedangkan biaya yang dikeluarkan petani dari usahatani padi berupa biaya tetap dan biaya variabel. Adapun biaya tetap yang dikeluarkan berupa biaya pajak lahan 
yang dikeluarkan setahun sekali dan penyusutan alat. Adapun alat yang biasa digunakan adalah cangkul, sabit, parang dan lain-lain. Biaya variabel adalah biaya dikeluarkan untuk pembelian pupuk, obat-obatan, bibit, dan penggunaan tenaga kerja baik tenaga kerja upahan maupun tenaga kerja dalam keluarga. Pendapatan diperoleh dengan mengurangi penerimaan dikurangi dengan total biaya. Adapun pendapatan yang diperoleh petani dalam usahatani padi di Desa Kanjilo Kecamatan Barombong Kabupaten Gowa dapat dilihat pada Tabel 1.

Tabel 1. Pendapatan rata-rata petani(Rp/ha/musim) dalam usahatani padi di Desa Kanjilo, Kecamatan Barombong Kabupaten Gowa

\begin{tabular}{clr}
\hline No. & Uraian & Nilai $(\mathrm{Rp})$ \\
\hline 1. & Penerimaan & 22.746 .334 \\
2. & Total Biaya & 3.544 .949 \\
3. & Pendapatan & 19.201 .386 \\
\hline
\end{tabular}

Sumber : Data Primer Setelah Diolah, 2019.

Hasil Penelitian menunjukkan bahwa petani memperoleh pendapatan dari kegiatan usahatani padi Rp. 19.201.386/ha/musim. Jika diliat dari hasil perhitungan pendapatan petani memiliki pendapatan yang relatif kecil disebabkan karena luas lahan yang mereka kelolah berkisar $0,1 \mathrm{Ha}$ hingga 0,8 ha (luasan usahatani $<1$ ha). Petani melakukan usahatani padi dalam setahun sebanyak 2-3 kali musim tanam bergantung pada jenis sawah tadah hujan atau beririgasi. Jenis sawah Didesa Kanjilo ada yang beririgasi dan ada juga tadah hujan. Jenis sawah ber irigasi membuat petani dapat melakukan usahatani sebanyak 3 kali dalam setahun.

Pendapatan usahatani padi bergantung pada luas lahan yang mereka garap. Berkurangnya lahan pertanian khususnya untuk tanaman padi disebabkan adanya kegiatan pembangunan yang meluas hingga daerah penyangga kota disebabkan karena adanya pertambahan jumlah penduduk yang menuntut tersedianya pemukiman dan kegiatan industri. Hal ini diperkuat oleh Ashari (2003), adanya konversi lahan menyebabkan adanya kerugian menurunnya lahan pertanian yang berdampak pada penurunan produksi dan pendapatan dari usahatani padi. Pendapatan merupakan salah satu indikator dari sisi ekonomi, walaupun pendapatan dari usahatani kecil tetapi tidak menyurutkan upaya mereka untuk menjalankan usahatani padi. Pendapatan yang kurang mereka lakoni dengan mencari strategi dalam memenuhi kebutuhan hidup.

\section{Persfektif Petani Secara Sosial dan Ekonomi}

\section{a. Secara Ekonomi}

Perhitungan pendapatan menggambarkan bahwa usahatani padi tidak memberikan pendapatan yang besar, sementara biaya hidup yang besar utamanya dalam hal pendidikan anak. Bagi petani memberikan pandangan bahwa usahatani padi cukup memberikan kontribusi dalam pendapatan keluarga dan juga dikonsumsi. Hal ini diungkapkan oleh R (32 tahun) salah satu responden yang menyatakan :

"Saya walaupun lahanku kecil yang penting bisajeka menanam padi bisa tommi kujual dapatka uang walaupun permusim dan ada tommi kasian kumakan"

Menurut Ellis (2000), mengemukakan klasifikasi sumber nafkah (income source) yang merupakan strategi nafkah yaitu :

a. Sektor on farm income, sektor ini mengacu pada pendapatan yang berasal dari tanah pertanian milik sendiri, baik yang diusahakan oleh pemilik tanah maupun diakses melalui sewa menyewa atau bagi hasil. 
b. Sektor non farm income, sektor ini mengacu pada pendapatan yang bukan berasal dari pertanian.

Petani bekerja dalam usahatani padi juga bekerja disektor non pertanian sebagai buruh bangunan, supir, buruh cuci,bengkel dan lain-lain. Petani melakoni pekerjaan secara on farm dan non farm. Hal ini diungkapkan oleh $\mathrm{H}$ (56 tahun), yang menyatakan :

"Biarmi sedikit kudapa dari tanam padi yang penting ada didapa dan bisa tommiki pakeki buat makan kasiang buat tambah-tambah keperluan lain terutama sekolah kucari tambahan jadi supir pete-pete"

Bekerja disektor non farm merupakan tuntutan kebutuhan keluarga selain itu perkembangan pembangunan menyediakan pekerjaan di luar sektor pertanian serta akses kekota dekat untuk mendapatkan pekerjaan disektor industri, jasa, serta perumahan. Selain itu pula mereka memanfaatkan lahan pekarangan untuk memenuhi kebutuhan sayuran bagi konsumsi dan dijual. Adapun jenis sayuran yang ditanam berupa : kangkung, kacang panjang, kemangi, terong, dan lain-lain. Hal ini diperkuat dengan pernyataan Amruddin dan Iqbal (2018), pemanfaatan lahan pekarangan di Desa Kanjilo untuk kebutuhan keluarga dan untuk ekonomis sehingga petani menjalankan fungsinya sebagai ketahanan pangan dengan melakukan usahatani padi dan ketahanan gizi dengan pemanfatan pekarangan. Responden pada penelitian ini ada petani laki-laki dan perempuan, bagi petani laki-laki, istri mereka berperan dalam pemanfatan pekarangan, sementara bagi perempuan berfungsi sebagai petani disawah juga sebagai petani dalam pemanfaatan pekarangan.

\section{b. Secara Sosial}

Secara sosial berbicara mengenai budaya,tradisi yang dipegang oleh petani. Kebanyakan petani mempertahankan tanah mereka dan melakukan kegiatan usahatani padi dengan pertimbangan bahwa tanah memberikan status sosial dan pelapisan sosial. Tanah memberikan pendapatan bagi keluarga dalam usahatani padi. Hal ini ditunjang oleh pernyataan Amruddin (2010), bahwa tanah memiliki peranan sebagai lambang status, memberikan penghidupan bagi keluarga dan stratifikasi sosial.

Hasil wawancara dengan salah satu petani B (50 tahun), menyatakan :

"Biarmi tanahku kecil yang penting saya masih punya tanah untuk digarap untuk tanam padi, banggaka kalau masih ada tanah kumiliki untuk menanam, bisa tommeka kasi makan anakku dan istriku. Kalo ada tanah naanggap tongki orang beradajeki”

Hal ini menjelaskan bahwa keberadaan tanah pertanian bagi petani memberikan arti secara sosial memberikan rasa kebanggaan, menunjukkan status sosial sebagai pemilik tanah walaupun dengan luasan yang kecil. (kurang dari $1 \mathrm{Ha}$ ). Hal ini juga merupakan alasan mengapa mereka mempertahankan tanah mereka dan melakukan usahatani padi. Desa Kanjilo merupakan wilayah pedesaan. Pada pedesaan tanah menjadi hal yang berharga karena sebagian penduduknya dalam sektor petanian/ Sehingga tanah memiliki nilai tertinggi dari hal apapun di pedesaan (Narwoko dan Suyanto, 2011). Selain itu pula, kelas sosial dimasyarakat (stratifikasi) menggambarkan bahwa yang memiliki tanah memiliki kelas yang lebih baik dipandangan masyarakat dibandingkan mereka yang tidak memiliki tanah pertanian.

Budaya tanaman padi telah dilakoni secara turun temurun, sehingga pengetahuan dan tata cara bertani dalam usahatani padi telah diperoleh dari orang tua mereka, demikian juga dengan tanah diwariskan secara turun temurun. Sehingga usahatani padi harus terus dilakukan walaupun dengan luasan yang kecil. Hal ini diungkapkan oleh salah satu responden (A, 48 tahun) yang menyatakan : 
"biarmi kecil lahan sawah yang kugarap yang penting tetapka bertani karena pekerjaan menanam padi sudah diwariskanka dari orang tua,dari kecilka turun kesawah membantu orang tua jadi inimi terus kukerja walau kecilji kudapa"

Hal ini menggambarkan bahwa usahatani padi adalah tradisi keluarga yang harus terus mereka jalankan walaupun mulai tergeser dengan adanya pembangunan diluar sektor pertanian (sektor industri dan perumahan).

\section{KESIMPULAN}

1. Pendapatan petani dari usahtani padi Rp.19.201.386/Ha/Musim, petani melakukan usahatani padi 2-3 kali selama setahun.Usahatani cukup menguntungkan bagi petani namun hasil yang diperoleh belum dapat memenuhi kebutuhan hidup mereka disebabkan tingginya biaya hidup.

2. Persfektif secara ekonomi bagi petani usahatani padi cukup memberikan kontribusi ekonomi serta ditunjang dengan melakukan strategi nafkah dengan cara bekerja diluar sektor pertanian (off farm) sebagai supir,buruh bangunan, usaha bengkel, buruh cuci dan lain-lain. Sedangkan Persfektif Sosial petani mempertahankan tanah pertanian untuk memenuhi konsumsi pangan, mempertahankan budaya dan tradisi dalam bercocok tanam, serta masih dianggap sebagai alat dalam stratifikassosial.

\section{DAFTAR PUSTAKA}

Amruddin, 2010. Pokok-pokok Sosiologi Pertanian. Makassar : Lembaga Penerbitan UNISMUH Makasar.

Amruddin. Muhammad Iqbal, 2018. Pemanfataan Lahan Pekarangan sebagai Upaya Pemenuhan Kebutuhan Keluarga Di Desa Kanjilo Kecamatan Barobong Kabupaten Gowa. Jurnal Ziraa'ah, Vol. 43 No. 1, hal. 70-76.

Ashari, 2003. Tinjauan tentang Alih fungsi Lahan sawah ke non sawah dan Dampaknya di Pulau Jawa. Forum Penelitian Agro Ekonomi, Vol. 21 No.2 hal. 83-98.

Badan Pusat Statistik, 2017. Gowa dalam Angka 2017. Makassar : BPS Sulawesi Selatan.

Ellis, F. 2000. Rural Livehood and Diversity in Development Countries. New York, Oxford University Press.

Irawan, Bambang, 2005. Konversi Lahan Sawah : Potensi, Dampak, Pola Pemanfaatan dan Faktor Determinan. Forum Penelitian Agro Ekonomi, Vol. 23 No.1, hal. 1-18.

Ken, Suratiyah. 2011. Ilmu Usahatani, Penebar Swadaya, Jakarta.

Narwoko, J. Dwi dan Suyanto. 2011. Sosiologi Teks Pengantar dan Terapan. Kencana Prenada Media Grup, Jakarta.

Sugiyono, 2010. Metode penelitian Pendidikan pendekatan Kualitatif, Kuantitatif, dan R\&D. Bandung : Alfabeta. 